\title{
Severe degenerative aortic stenosis with preserved ejection fraction does not change adipokines serum levels
}

\author{
Katarzyna Mizia-Stec ${ }^{1}$, Tomasz Bochenek ${ }^{1}$, Błażej Kusz ${ }^{1}$, \\ Magdalena Mizia-Szubryt ${ }^{1}$, Agnieszka Sikora-Puz ${ }^{2}$, Klaudia Gieszczyk-Strózik ${ }^{1}$ \\ ${ }^{1}$ First Department of Cardiology, School of Medicine in Katowice, \\ Medical University of Silesia, Katowice, Poland \\ ${ }^{2}$ Second Department of Cardiology, School of Medicine in Katowice, \\ Medical University of Silesia, Katowice, Poland
}

\begin{abstract}
Background: The role of the adipokines in the pathogenesis of aortic stenosis (AS) is not well established. The aim was to evaluate the relationship between adipokines and clinical characteristics as well as echocardiographic indices and noninvasive markers of vascular remodeling in patients with severe $A S$ with preserved ejection fraction $(E F)$.

Methods: Sixty-five patients (F/M: 38/27; age: $68.3 \pm 9.0$ years; body mass index [BMI]: $29.6 \pm 4.3$ $\mathrm{kg} / \mathrm{m}^{2}$ ) with severe AS with preserved EF: 33 patients with paradoxical low-flow low-gradient AS (PLFLG $A S)$ and 32 patients with normal flow high-gradient $A S$ (NFHG AS) were prospectively enrolled into the study. Twenty-four subjects (F/M: 14/10; age: $65.4 \pm 8.7$ years; BMI: $29.6 \pm 4.3 \mathrm{~kg} / \mathrm{m}^{2}$ ) who matched as to age, sex, BMI and coronary artery disease (CAD) constituted the control group (CG). Clinical data and markers of vascular remodeling were related to the serum adipokines.

Results: There were no differences in the adipokines concentrations in the AS/CG. Patients with AS and coexisting $C A D$ were characterized by decreased serum adiponectin $(9.9 \pm 5.5 \mathrm{vs} .12 .7 \pm 5.8 \mu \mathrm{g} / \mathrm{mL}$, $p=0.040)$ and leptin $(8.3 \pm 7.8 \mathrm{vs} .21 .6 \pm 17.1 \mathrm{ng} / \mathrm{mL}, p<0.001)$ levels compared to subjects without $C A D$. There were no differences in the serum adipokines concentrations between patients with PLFLG AS and NFHG AS. Systemic hypertension, diabetes, hyperlipidemia or markers of vascular remodeling did not discriminate adipokines concentrations. Multivariate regression analysis indicated that age $(F=3.02 ; p=0.015)$ and $E / E^{\prime}$ index $(F=0.87, p=0.032)$ were independent predictors of the adiponectin level in the AS group.

Conclusions: The presence of AS with preserved EF did not change the adipokine serum profile. Adipokines levels were modified by coexisting atherosclerosis but not the typical cardiovascular risk factors or the hemodynamic type of AS. (Cardiol J 2019; 26, 5: 483-492)
\end{abstract}

Key words: echocardiography, aortic stenosis, atherosclerosis, adipokines, vascular remodeling

\section{Introduction}

Adipokines are involved in various inflammatory and metabolic processes, including atherosclerosis, hypertension and dyslipidemia. Their standard panel includes adiponectin, leptin resistin and visfatin.

Adiponectin has antiatherogenic and antiinflammatory effects on endothelial cells and macrophages $[1,2]$, which are caused by an increase in

Address for correspondence: Błażej Kusz, MD, First Department of Cardiology, School of Medicine in Katowice, Medical University of Silesia, ul. Ziołowa 45/47, 40-635 Katowice, Poland, tel: 796-680-604, e-mail: kuszblazej@gmail.com

Received: 21.12.2016

Accepted: 13.04.2017 
nitrix oxide (NO) production, a reduction of adhesion molecules in the endothelial cells, inhibition of macrophages cytokine production and foam cell formation supression [3-5]. Clinical studies implicate hypoadiponectinemia in the pathogenesis of diabetes mellitus (DM) type 2, arterial hypertension (HA), coronary artery disease (CAD) and left ventricular (LV) hypertrophy [6-9].

Leptin, in turn, may have an impact on cardiac hypertrophy and may be associated with an increased cardiovascular risk as plasma leptin concentrations were shown to be elevated in patients with LV dysfunction and heart failure [10-12].

Resistin, which has primarily been suggested as a hormone that potentially links obesity to DM, was later proved to regulate the processes of the atherosclerosis and cardiovascular disease as well $[13,14]$.

Visfatin, which was originally described as a protein secreted by visceral fat that mimics insulin effects, turned out to have a relationship with cardiovascular diseases. It can promote foam cell formation and angiogenesis [15-17]. Elevated visfatin serum levels were found in patients with acute myocardial infarction [18].

Adipokines may thus be considered to be a network that influences metabolic states and has the potential to impact directly upon the metabolic homeostasis of a system. Their role in other pathological cardiovascular conditions is not yet well known. Assuming that there are some similarities between the pathophysiology of calcific aortic valve (AV) disease (AVD) and atherosclerosis, those proteins may likewise play a potential role in its development. Moreover, in aortic stenosis (AS) with a low-gradient and preserved ejection fraction $(\mathrm{EF})$, a clinical profile of patients with a higher incidence of obesity, HA and increased peripheral vascular resistance may especially be associated with adipokines abnormalities [19,20].

Thus, the aim of this study was to evaluate the relationship between adipokines and the clinical characteristics as well as echocardiographic indices and noninvasive markers of vascular remodeling in patients with severe AS with preserved EF.

\section{Methods}

\section{Population}

Sixty-five patients (F/M: 38/27; age: $68.3 \pm$ \pm 9.0 years; body mass index [BMI]: $29.6 \pm 4.3 \mathrm{~kg} / \mathrm{m}^{2}$ ) with severe degenerative AS (New York Heart Association [NYHA] I/II/III: 20/37/8) with preserved LVEF (> 50\%) (Table 1) - 33 patients with paradoxical low-flow/low-gradient AS (PLFLG AS) and 32 patients with normal flow/high-gradient AS (NFHG AS) were prospectively enrolled into the study. Twenty-four healthy subjects (F/M: 14/10; age: $65.4 \pm 8.7$ years; BMI: $29.6 \pm 4.3 \mathrm{~kg} / \mathrm{m}^{2}$ ) who matched as to age, sex and BMI constituted the control group (CG). Clinical data, body composition, echocardiography, coronary angiography and noninvasive markers of vascular remodeling were examined. The above data were related to the serum adiponectin, leptin, resistin and visfatin levels. The trial was conducted between 2011 and 2013 in the Departments of Cardiology and Cardiac Surgery at the Silesian Medical Center in Katowice and included patients with severe AS and any symptoms that are related to AS. The exclusion criteria included actual indications for coronary revascularization, segmental wall motion abnormalities, a bad acoustic window (5 or more segments that could not be analyzed), non-sinus rhythm, a bicuspid AV, moderate/severe mitral regurgitation, acute and chronic inflammatory diseases including myocarditis and endocarditis (in the 3 preceding months), NYHA IV, dilatation of the aortic root, Marfan syndrome, acute coronary syndromes, recurrent supraventricular and ventricular arrhythmias, acute and chronic kidney disease (glomerular filtration rate $<60 \mathrm{~mL} / \mathrm{min} / 1.73 \mathrm{~m}^{2}$ ), malignancies, autoimmune diseases, immunosuppressive therapy, coexisting psychiatric or neurological disorders and alcohol or drug abuse. The study protocol was approved by the local Bioethics Committee. Each patient gave written consent to participate in the study.

\section{Clinical data}

The clinical characteristics of the patients in the study included their clinical status (NYHA/CCS class), anthropometric data (height, BMI, waist to hip ratio [WHR]), a physical examination and medical history (concomitant diseases, pharmacotherapy and smoking status). Body composition was determined by an impedance analysis using Bodystat.

\section{Laboratory tests}

Blood samples $(10 \mathrm{~mL})$ were drawn from the peripheral vein from patients in the supine decubitus position in the morning after an overnight fast. Total cholesterol, high- and low-density lipoprotein cholesterol fractions, triglycerides and creatinine serum concentrations were measured using routine methods.

Serum levels of adipokines (intra-assay variability ranged: 6-9\%) were measured using an enzyme-linked immunosorbent assay. A single-use kit was used in order to avoid inter-assay variability. 


\section{Coronary angiography}

Coronary angiography was performed in all patients. A diagnosis of CAD was established in cases of $\mathrm{a} \geq 70 \%$ diameter narrowing in at least one of the three major epicardial coronary arteries.

\section{Ultrasound assessment}

Two-dimensional transthoracic echocardiography was performed in all of the patients by an experienced sonographer according to guidelines of the European Society of Echocardiography [21]. An ultrasound system (GE Vivid 9) equipped with a 3.5-1.75 MHz transthoracic transducer was used for all of the patients.

\section{Left ventricular geometry and function}

Two-dimensional M-mode echocardiography was used to measure LV dimensions in the left parasternal long-axis view. The $\mathrm{LV}$ end-diastolic diameter (LVEDD), posterior wall (PW) and septal wall thickness (IVS) were measured at the end-diastole (d). The LV end-systolic diameter (LVESD) was also obtained. The LV mass (LVM) was calculated according to the following formula: $\mathrm{LVM}=1.04 \times$ $\times\left[(\mathrm{LVEDD}+\mathrm{IVS}+\mathrm{PW})^{3}-\mathrm{LVEDD}^{3}\right]-13.6$ and indexed for body surface area (BSA) to obtain the LVM index (LVMI). The values of LV end-diastolic (LVEDV) and end-systolic volume (LVESV) were measured using the Simpson method; LVEF, stroke volume (SV) and $\mathrm{LV}$ cardiac output (CO) were also obtained. The values of the LVM, SV and CO were indexed for body surface area (BSA).

\section{Severity of aortic valve stenosis/effective} orifice area of the implanted prosthesis

Maximal (Pmax) and mean (Pmean) transvalvular pressure gradients were obtained using a modified Bernoulli equation and the effective orifice area (EOA) was measured using the continuity equation. The LV outflow tract (LVOT) dimension was measured three to four times and finally the mean LVOT value was used in the automatically calculated EOA. In order to avoid any mistakes, we compared EOA calculated by VTI and the Vmax and SV measured by Simpson's formula and this was obtained using the Bernoulli equation. The values of the EOA were indexed for BSA. The valvuloarterial impedance $(\mathrm{Zva})$ was calculated according to the recommended equation [21].

\section{Noninvasive markers of vascular remodeling Flow-mediated dilatation (FMD)}

The examinations were performed in the morning in a room at $22^{\circ} \mathrm{C}$ after a 15 -min rest and an overnight fast. Smoking cigarettes was not allowed for the previous $24 \mathrm{~h}$. The subjects lay supine with their heads slightly extended. All of the measurements of brachial arteries (BA) were performed above the antecubital fossa in the longitudinal plane using a sphygmomanometric cuff on the proximal portion of the arm. The right BA was scanned at rest, during reactive hyperemia and following the administration of sublingual nitroglycerin $(0.5 \mathrm{mg})$. Reactive hyperemia was induced with the inflation of a sphygmomanometer cuff to $200 \mathrm{~mm} \mathrm{Hg}$ in order to occlude arterial inflow for $3 \mathrm{~min}$. BA diameter (BAd) and blood flow were obtained during the 50-60 s after cuff deflation. Blood flow was measured from the pulsed Doppler signal and arterial diameters were taken from the anterior to the posterior " $\mathrm{M}$ " line at the end diastole. Images were acquired with electrocardiogram gating with the end of diastole corresponding to the onset of the $\mathrm{R}$ wave. The baseline and after-cuff deflation measurements were used for the FMD calculation (percent increase of the artery diameter compared to the baseline results) estimation. Endogenous vasodilatory capability, independent of BAd, was defined as the FMD $\times$ BAd index and calculated for allsubjects.

\section{Pulse wave velocity (PWV) assessment}

Two pulse waves were obtained transcutaneously at the base of the neck for the right common carotid artery and over the right femoral artery. Transit time was measured as the time between the foot of the pulse wave and the foot of the $R$ wave. Pulse transit time was determined as the average of 10 consecutive beats. Time delay ( $t$ ) was calculated as the difference between these two transit times. The distance (d) traveled by the pulse wave was measured over the body surface as the distance between two recording sites. Pulse wave velocity was calculated as $\mathrm{PWV}=\mathrm{d}$ (meters)/t (seconds).

\section{Augmentation index (AIx)}

The examination was performed using the applanation tonometry - Applanation (SphygmoCor system created by the Australian company AtCorMedical).

The test was performed in a lying position after a 5-min adaptation with the inner side of the hand facing upward. The tonometer head was placed on the wrist at the most palpable pulse. The system processed a registered pulse wave of the radial artery and marked the pulse curve in the ascending aorta. 
Table 1. Characteristics of the study group and controls.

\begin{tabular}{|c|c|c|c|}
\hline Variable & AS patients $(n=65)$ & Controls $(n=24)$ & $\mathbf{P}$ \\
\hline Women/men & $38(58 \%) / 27(42 \%)$ & $14(58 \%) / 10(42 \%)$ & 0.7 \\
\hline Age [years] & $68.3 \pm 9$ & $69.1 \pm 8.1$ & 0.9 \\
\hline NYHA class I/II/III & $20(31 \%) / 37(57 \%) / 8(12 \%)$ & $6(25 \%) / 17(71 \%) / 1(4 \%)$ & 0.9 \\
\hline CCS class $0 / 1 / 2 / 3$ & $15(23 \%) / 20(31 \%) / 28(43 \%) / 2(3 \%)$ & $4(17 \%) / 8(33 \%) / 12(50 \%) / 0$ & 0.9 \\
\hline Height $[\mathrm{cm}]$ & $164 \pm 10$ & $165 \pm 11$ & 0.9 \\
\hline Weight [kg] & $78.0 \pm 13.7$ & $77.1 \pm 14.1$ & 0.9 \\
\hline BMI $\left[\mathrm{kg} / \mathrm{m}^{2}\right]$ & $29.6 \pm 4.3$ & $28.3 \pm 4.3$ & 0.5 \\
\hline $\mathrm{BSA}\left[\mathrm{m}^{2}\right]$ & $1.87 \pm 0.21$ & $1.86 \pm 0.22$ & 0.9 \\
\hline WHR $[\mathrm{cm}]$ & $0.93 \pm 0.1$ & $0.92 \pm 0.06$ & 0.9 \\
\hline Body fat $(\%]$ & $33.1 \pm 2.8$ & $32.8 \pm 3.1$ & 0.8 \\
\hline Heart rate $[\mathrm{bpm}]$ & $68.0 \pm 10.4$ & $67.3 \pm 8.1$ & 0.9 \\
\hline Systolic BP [mmHg] & $127.1 \pm 21.7$ & $124.2 \pm 17.8$ & 0.9 \\
\hline Diastolic BP [mmHg] & $82.6 \pm 12.1$ & $74.5 \pm 7.4$ & 0.7 \\
\hline Coronary artery disease & $26(40 \%)$ & $12(50 \%)$ & 0.7 \\
\hline Hypertension & $53(82 \%)$ & $17(71 \%)$ & 0.8 \\
\hline Diabetes & $16(25 \%)$ & $8(33 \%)$ & 0.7 \\
\hline Current smoking & $6(9 \%)$ & $4(17 \%)$ & 0.7 \\
\hline Smoking history & $12(18 \%)$ & $7(29 \%)$ & 0.7 \\
\hline Triglycerides [mg/dL] & $138 \pm 48$ & $142 \pm 55$ & 0.7 \\
\hline Total cholesterol $[\mathrm{mg} / \mathrm{dL}]$ & $188 \pm 51$ & $184 \pm 47$ & 0.8 \\
\hline HDL cholesterol [mg/dL] & $45 \pm 12$ & $48 \pm 14$ & 0.8 \\
\hline LDL cholesterol [mg/dL] & $112 \pm 38$ & $117 \pm 37$ & 0.9 \\
\hline Glomerular filtration rate $[\mathrm{mL} / \mathrm{min}]$ & $87.8 \pm 12.3$ & $89.6 \pm 8.3$ & 0.9 \\
\hline
\end{tabular}

Data are presented as the mean \pm standard deviation or number (percentage); AS — aortic stenosis; BMI — body mass index; BSA — body surface area; BP — blood pressure; CCS — Canadian Cardiovascular Society grading of angina pectoris; HDL — high-density lipoprotein cholesterol; LDL - low-density lipoprotein cholesterol; NYHA — New York Heart Association functional classification; WHR — waist-to-hip ratio

The analyzed susceptibility of the vessels was defined by the following parameters: central systolic and diastolic blood pressure levels (aortic systolic and diastolic pressure), central pulse pressure (aortic pulse pressure) and the value of the index gain (AIx).

\section{Statistical analysis}

Statistical analysis was performed using MedCalc for Windows, version 10.0. All of the text and table results are expressed as means \pm standard deviation (SD) or as a number (percentage). The normal distribution result was analyzed using the Kolmogorov-Smirnov test. In the case of abnormal distribution, a logarithmic transformation was used.

The baseline clinical parameters and the results of the ancillary investigations were compared using the two-sample t-tests for normally distributed continuous variables (Student's t-test); in the case of an abnormal distribution, the Mann-Whitney U test was used. Categorical variables were compared using the $\chi^{2}$ test. The Spearman rank-order test or Pearson correlations were used to determine the relationship between the variables. Multivariable linear regression was used to assess the independent predictors of the adipokine levels; parameters that were associated with plasma adipokines at the level of $p<0.1$ on the univariate analysis were analyzed. A value of $\mathrm{p}<0.05$ was considered statistically significant.

\section{Results}

\section{Clinical data}

The clinical characteristics of AS patients and controls did not reveal any significant differences (Table 1).

There were no significant differences in LVESV, LVEDV, LVEF as well as in CO and the cardiac index (CI) between the patients with AS and the CG. LVMI was obviously significantly higher in the AS group $\left(150.4 \pm 32.6\right.$ vs. $\left.115.2 \pm 21.7 \mathrm{~g} / \mathrm{m}^{2}\right)$. 
Table 2. Results of transthoracic echocardiography in the study group and controls.

\begin{tabular}{lccc}
\hline Variable & AS patients $(\mathbf{n}=\mathbf{6 5})$ & Controls $(\mathbf{n}=\mathbf{2 4})$ & $\mathbf{P}$ \\
\hline LVESV $[\mathrm{mL}]$ & $47.0 \pm 19.1$ & $47.8 \pm 17.1$ & 0.92 \\
LVEDV $[\mathrm{mL}]$ & $115.9 \pm 32.6$ & $118.4 \pm 39.1$ & 0.91 \\
LVEF $[\%]$ & $60.5 \pm 6.5$ & $60.4 \pm 6.4$ & 0.95 \\
CO $[\mathrm{L} / \mathrm{min}]$ & $4.4 \pm 1.2$ & $4.8 \pm 1.7$ & 0.87 \\
Cl $\left[\mathrm{L} / \mathrm{min} / \mathrm{m}^{2}\right]$ & $2.7 \pm 0.7$ & $2.8 \pm 0.8$ & 0.91 \\
LVMI $\left[\mathrm{g} / \mathrm{m}^{2}\right]$ & $150.4 \pm 32.6$ & $115.2 \pm 21.7$ & 0.009 \\
AV anulus $[\mathrm{mm}]$ & $21.5 \pm 1.9$ & $22.9 \pm 2.1$ & 0.013 \\
Pmax $[\mathrm{mmHg}]$ & $95.8 \pm 24.7$ & - & - \\
Pmean $[\mathrm{mmHg}]$ & $58.6 \pm 16.6$ & - & - \\
iEOA $\left[\mathrm{cm}^{2} / \mathrm{m}^{2}\right]$ & $0.37 \pm 0.08$ & - & - \\
Zva $\left[\mathrm{mmHg} / \mathrm{mL} / \mathrm{m}^{2}\right]$ & $5.6 \pm 1.1$ & - & - \\
\hline
\end{tabular}

Data are presented as the mean \pm standard deviation; AS - aortic stenosis; AV - aortic valve; CO - cardiac output; iEOA - indexed effective orifice area; LVEF — left ventricular ejection fraction; LVEDV — left ventricular end-diastolic volume; LVESV — left ventricular end-systolic volume; LVMI - left ventricular mass index; Pmax — maximum gradient across aortic valve; Pmean — mean gradient across aortic valve; Zva - valvuloarterial impedance

Table 3. Baseline vascular parameters of the study groups.

\begin{tabular}{lccc}
\hline & AS patients $(\mathbf{n}=\mathbf{6 5})$ & Controls $(\mathbf{n}=\mathbf{2 4})$ & $\mathbf{P}$ \\
\hline FMD [\%] & $11.57 \pm 5.8$ & $13.22 \pm 5.2$ & 0.205 \\
BAd [mm] & $3.46 \pm 0.5$ & $3.58 \pm 0.6$ & 0.799 \\
FMD $\times$ BAd & $36.28 \pm 8.5$ & $43.51 \pm 9.8$ & 0.043 \\
PWV [m/s] & $9.9 \pm 2.7$ & $7.8 \pm 3.2$ & 0.089 \\
Aortic SP [mmHg] & $123.2 \pm 10.5$ & $131.2 \pm 11.2$ & 0.744 \\
Aortic DP [mmHg] & $69.3 \pm 15.2$ & $72.5 \pm 11.6$ & 0.804 \\
AP [mmHg] & $49 \pm 14.1$ & $56.4 \pm 12.3$ & 0.462 \\
Alx [\%] & $33.0 \pm 12.8$ & $33.0 \pm 12.8$ & 0.281 \\
\hline
\end{tabular}

Data are presented as the mean \pm standard deviation; AS — aortic stenosis; Alx — augmentation index; AP — arterial pressure; BAd — brachial artery diameter; DP — diastolic pressure; FMD — flow-mediated dilatation; PWV — pulse wave velocity; SP — systolic pressure

The AV annulus was significantly smaller in the AS group $(21.5 \pm 1.9$ vs. $22.9 \pm 2.1 \mathrm{~mm}, \mathrm{p}=0.013)$. The mean maximum AV gradient (Pmax) in the AS group was $95.8 \pm 24.7 \mathrm{mmHg}$ while the mean gradient (Pmean) was $58.6 \pm 16.6 \mathrm{mmHg}$. The indexed EOA was calculated for $0.37 \pm 0.08 \mathrm{~cm}^{2} /$ $/ \mathrm{m}^{2}$ in the AS group (Table 2).

There were no significant differences observed in the FMD value between the AS and the CG. There were also no differences in the BAd. However, the FMD $\times$ BAd index remained significantly higher in the CG.

There were also no significant differences in the PWV between the two examined groups. Aortic systolic, diastolic pressure and pulse were insignificantly higher in the CG. Value of the index and the gain remained same in both groups (Table 3 ).

\section{Clinical data - PLFLG AS vs. NFHG AS}

The mean age of both groups remained simi$\operatorname{lar}(68.5 \pm 7.9$ for PLFLG AS vs. $68.1 \pm 10.2$ for NFHG AS) as well as BMI (29.48 \pm 4.2 vs. $29.8 \pm$ $\left.\pm 4.6 \mathrm{~kg} / \mathrm{m}^{2}\right)$, WHR $(0.9 \pm 0.1$ vs. $0.9 \pm 0.1)$, systolic $(133.9 \pm 22.6$ vs. $140.3 \pm 20.5 \mathrm{mmHg})$ and diastolic $(82.9 \pm 12.3$ vs. $82.3 \pm 12.1 \mathrm{mmHg})$ blood pressure.

There were significant differences between the PLFLG AS and NFHG AS groups in CO (3.7 \pm \pm 0.8 vs. $5.6 \pm 1.6 \mathrm{~L} / \mathrm{min}, \mathrm{p}<0.001)$ and $\mathrm{CI}(2.1 \pm$ \pm 0.4 vs. $\left.2.9 \pm 0.6 \mathrm{~L} / \mathrm{min} / \mathrm{m}^{2}, \mathrm{p}<0.001\right), \mathrm{LVMI}$ $\left(153.2 \pm 26.7\right.$ vs. $\left.136.1 \pm 31.2 \mathrm{~g} / \mathrm{m}^{2}, \mathrm{p}=0.032\right)$ and $\mathrm{Zva}\left(6.2 \pm 1.2\right.$ vs. $4.8 \pm 0.9 \mathrm{mmHg} / \mathrm{mL} / \mathrm{m}^{2}$, $\mathrm{p}<0.001)$. Differences were observed in Pmean values, which were significantly lower in the PLFLG AS group $(51.1 \pm 16.9$ vs. $60.4 \pm 16.3 \mathrm{mmHg}$, 
Table 4. Serum adipokines levels in the study group and controls.

\begin{tabular}{lccc}
\hline & AS patients $(\mathbf{n}=65)$ & Controls $(\mathbf{n}=24)$ & P \\
\hline Adiponectin $[\mu \mathrm{g} / \mathrm{mL}]$ & $11.57 \pm 5.8$ & $11.59 \pm 4.2$ & 0.674 \\
Leptin $[\mathrm{ng} / \mathrm{mL}]$ & $16.28 \pm 13.5$ & $21.51 \pm 19.8$ & 0.44 \\
Visfatin $[\mathrm{ng} / \mathrm{mL}]$ & $2.93 \pm 2.2$ & $2.80 \pm 2.2$ & 0.734 \\
Resistin $[\mathrm{ng} / \mathrm{mL}]$ & $6.37 \pm 5.5$ & $7.13 \pm 4.6$ & 0.281 \\
\hline
\end{tabular}

Data are presented as the mean \pm standard deviation; AS - aortic stenosis

$\mathrm{p}=0.02$ ). The mean values of AV annulus, Pmax and iEOA were similar.

There were no noticeable differences in PWV $(7.5 \pm 3.3$ vs. $6.5 \pm 2 \mathrm{~m} / \mathrm{s})$ and in FMD $(15.3 \pm 11$ vs. $18.6 \pm 10 \%)$.

No significant differences were observed between all adipokine levels in patients with PLFLG AS vs. NFHG AS.

\section{Serum adipokines levels in the study} group and controls

There were no significant differences in the serum adiponectin, leptin, visfatin and resistin concentrations in the AS and CG (Table 4).

\section{Serum adipokines levels in the study group} regarding clinical characteristics

Patients with AS and co-existing CAD were characterized by decreased serum adiponectin $(9.9 \pm$ \pm 5.5 vs. $12.7 \pm 5.8 \mu \mathrm{g} / \mathrm{mL}, \mathrm{p}=0.040)$ and leptin $(8.3 \pm 7.8$ vs. $21.6 \pm 17.1 \mathrm{ng} / \mathrm{mL}, \mathrm{p}<0.001)$ levels compared to subjects without CAD. There were no significant differences in visfatin $(2.4 \pm 2.0 \mathrm{vs}$. $3.3 \pm 2.4 \mathrm{ng} / \mathrm{mL}, \mathrm{p}=0.074)$ and resistin levels $(5.00 \pm 4.2$ vs. $7.28 \pm 6.1 \mathrm{ng} / \mathrm{mL}, \mathrm{p}=0.102)$ (Table 5$)$.

There were no significant differences in serum adipokines concentrations between patients with concomitant HA. Patients with AS and DM had an insignificantly lower adiponectin level $(10 \pm 5.9 \mathrm{vs}$. $12.26 \pm 5.6, \mathrm{p}=0.052 \mu \mathrm{g} / \mathrm{mL}$ ) (Table 5).

There were also no significant differences in the serum adipokine concentrations between patients with PLFLG AS and NFHG AS (Table 5).

\section{Regression analysis}

The adiponectin levels correlated with age $(\mathrm{r}=0.464, \mathrm{p}<0.001)$, BMI $(\mathrm{r}=-0.334, \mathrm{p}=$ $=0.006)$, body fat percentage $(r=-0.315, p=0.011)$, LVMI $(r=-0.256, p=0.039), \operatorname{LV~SVi~}(r=-0.327$, $\mathrm{p}=0.008)$ and the $\mathrm{E} / \mathrm{E}^{\prime}$ index $(\mathrm{r}=-0.268$, $\mathrm{p}=0.022)$ (Table 6).

Leptin levels correlated with BMI $(r=0.456$, $\mathrm{p}<0.001)$, body fat percentage $(\mathrm{r}=0.522$, $\mathrm{p}<0.001)$ and $\operatorname{iEOA}(\mathrm{r}=-0.290, \mathrm{p}=0.019)($ Table 6$)$.
Multivariate regression analysis indicated age $(\mathrm{F}=3.02 ; \mathrm{p}=0.015)$ and the $\mathrm{E} / \mathrm{E}^{\prime}$ index $(\mathrm{F}=0.87, \mathrm{p}=0.032)$ as independent predictors of the adiponectin level in the AS group.

\section{Discussion}

In the population with AS with preserved EF, some clinical and metabolic indices may play a pivotal role for the progression of the disease and its symptomatology. This is why the serum adipokines concentrations were compared between AS patients and the controls - there were no differences observed. Moreover, the hypothesis that the CAD, HA, DM, vascular parameters influenced the adipokine serum levels was verified. This verification was a negative value in regard to the $\mathrm{HA}, \mathrm{DM}$ and vascular indices. Patients with AS and co-existing $\mathrm{CAD}$ were characterized by decreased adiponectin and leptin levels compared to the subjects without CAD. This is an important finding of the study, especially that low serum levels of adiponectin have been recognized as a risk factor for atherosclerotic disease [22]. It should be noted that the protective mechanism of adiponectin, which has an influence on the progression of atherosclerosis and is associated with increasing apolipoprotein A1 and high-density lipoprotein cholesterol, which have beneficial effects on lipid metabolism [23].

When discussing the role of adiponectin in AS patients, we may take into account the data that describes the adiponectin levels in non-AS patients. In the literature, there are mainly data on adiponectin levels in patients with CAD $[24,25]$ or metabolic disorders [26] but limited data on the role of adiponectin in AS pathogenesis. Low adiponectin concentrations are well documented in patients with CAD [24]. Low adiponectin contributes to coronary plaque vulnerability [25]. In this study, patients with $\mathrm{AS}$ and co-existing $\mathrm{CAD}$ were characterized by decreased serum adiponectin and leptin levels compared to subjects without CAD. It was suspected that the same CAD-related mechanism of hypoadiponectinemia was present in the presented group. 
Table 5. Serum adipokines levels in the study group regarding clinical characteristic.

\begin{tabular}{lccc}
\hline Coronary artery disease (CAD) & CAD (+) & CAD (-) & P \\
\hline Adiponectin $[\mu \mathrm{g} / \mathrm{mL}]$ & $9.87 \pm 5.5$ & $12.7 \pm 5.8$ & 0.040 \\
Leptin $[\mathrm{ng} / \mathrm{mL}]$ & $8.34 \pm 7.8$ & $21.56 \pm 17.1$ & 0.001 \\
Visfatin $[\mathrm{ng} / \mathrm{mL}]$ & $2.38 \pm 2.0$ & $3.31 \pm 2.4$ & 0.074 \\
Resistin $[\mathrm{ng} / \mathrm{mL}]$ & $5.00 \pm 4.2$ & $7.28 \pm 6.1$ & 0.102 \\
\hline Arterial hypertension (AH) & HA (+) & HA (-) & P \\
\hline Adiponectin $[\mu \mathrm{g} / \mathrm{mL}]$ & $11.64 \pm 5.8$ & $11.26 \pm 5.9$ & 0.754 \\
Leptin $[\mathrm{ng} / \mathrm{mL}]$ & $16.35 \pm 15.3$ & $15.95 \pm 13.9$ & 0.741 \\
Visfatin $[\mathrm{ng} / \mathrm{mL}]$ & $2.99 \pm 2.1$ & $2.70 \pm 2.1$ & 0.227 \\
Resistin $[\mathrm{ng} / \mathrm{mL}]$ & $6.40 \pm 5.4$ & $6.23 \pm 6.1$ & 0.750 \\
\hline Diabetes $\mathrm{mellitus} \mathrm{(DM)}$ & $\mathrm{DM}(+)$ & $\mathrm{DM}(-)$ & $\mathbf{P}$ \\
\hline Adiponectin $[\mu \mathrm{g} / \mathrm{mL}]$ & $9.95 \pm 5.9$ & $12.26 \pm 5.6$ & 0.052 \\
Leptin $[\mathrm{ng} / \mathrm{mL}]$ & $10.62 \pm 8.9$ & $18.13 \pm 16.9$ & 0.183 \\
Visfatin $[\mathrm{ng} / \mathrm{mL}]$ & $2.87 \pm 2.4$ & $2.96 \pm 2.2$ & 0.957 \\
Resistin $[\mathrm{ng} / \mathrm{mL}]$ & $7.53 \pm 6.7$ & $5.99 \pm 4.6$ & 0.654 \\
\hline Stroke $\mathrm{volume} \mathrm{index} \mathrm{(SVi)}$ & $\mathrm{SVi}<35 \mathrm{~mL} / \mathrm{m}^{2}(\mathrm{PLFLG} \mathrm{AS)}$ & $\mathrm{SVi} \geq 35 \mathrm{~mL} / \mathrm{m}^{2}$ (NFHG AS) & P \\
\hline Adiponectin $[\mu \mathrm{g} / \mathrm{mL}]$ & $12.19 \pm 5.4$ & $10.92 \pm 6.2$ & 0.259 \\
Leptin $[\mathrm{ng} / \mathrm{mL}]$ & $17.50 \pm 14.1$ & $15.02 \pm 6.9$ & 0.311 \\
Visfatin $[\mathrm{ng} / \mathrm{mL}]$ & $3.09 \pm 2.4$ & $1.78 \pm 2.1$ & 0.507 \\
Resistin $[\mathrm{ng} / \mathrm{mL}]$ & $6.76 \pm 4.6$ & $5.96 \pm 3.9$ & 0.718 \\
\hline
\end{tabular}

Data are presented as the mean \pm standard deviation; PLFLG AS — paradoxical low-flow low-gradient aortic stenosis; NFHG AS — normal flow high gradient aortic stenosis

Table 6. Regression analysis in the study group with adipokines as dependent variables.

\begin{tabular}{lcc}
\hline & $\begin{array}{c}\text { Correlation } \\
\text { coefficient }\end{array}$ & P \\
\hline Adiponectin & 0.464 & $<0.001$ \\
Age & -0.334 & 0.006 \\
Body mass index & -0.315 & 0.011 \\
Body fat\% & -0.256 & 0.039 \\
Left ventricular mass index & -0.327 & 0.008 \\
Stroke volume index & -0.268 & 0.022 \\
E/E' & & \\
Leptin & 0.456 & $<0.001$ \\
Bod mass index & 0.522 & $<0.001$ \\
Body fat\% & -0.290 & 0.019 \\
Indexed effective orifice area & & \\
Resistin & 0.269 & 0.033 \\
Pulse wave velocity & & \\
\hline
\end{tabular}

The available data on the role of adipokines in AS are limited to some problems. Recently, Gucuk Ipek et al. [27] showed, similar to the present findings, that there is no relationship between the adiponectin levels and calcific AVD. In contrast, Kolasa-Trela et al. [28] published an article suggesting that adipokines may be involved in the progression of AS. In 2010, Mohty et al. [29] observed that older patients with AS had a higher plasma level of resistin, which was associated with the degree of valvular calcification and inflammation. In their next paper, they showed that adiponectin may play a protective role against the inflammatory process and progression of calcific AVD [30]. They hypothesized that adiponectin might be partly responsible for the association between metabolic syndrome and calcific AVD. Concentrations of adiponectin were persistently reduced in patients with metabolic syndrome and this was the first demonstration of its negative association with the progression of AS. This observation is in accordance with the present findings and from a practical point of view - the reduced circulating level of adiponectin may be associated with a more rapid progression of AS stenosis and enhanced valvular inflammation.

The next step of analysis involved the hemodynamic profiles of patients with AS and preserved EF. 
Well-documented literature data as well as our previous findings indicated differences in demographics, the frequency of concomitant disease and systemic vascular resistance between populations with NFHG and PLFLG AS. Patients with PLFLG AS are characterized by a higher frequency of females, HA, LV hyperthrophy, increased systemic vascular resistance and finally lower SVi [19, 20]. Although our subpopulation with PLFLG AS had a limited number of patients, it was representative of the above-mentioned characteristics. Regardless of different clinical characteristics of NFHG and PLFLG patients, there were no differences in adipokines concentrations in these groups.

Adiponectin, and also leptin concentrations, correlated with standard obesity indices (BMI, body fat\%). This observation is in concordance with previous data. It was demonstrated that lowlevel adiponectin subjects were characterized by a significantly higher prevalence of some cardiometabolic comorbidities (obesity, visceral obesity, DM, insulin resistance, LV hypertrophy, metabolic syndrome, CAD) [26, 31, 32].

Interesting relationships were observed with regard to the adiponectin levels. Adiponectin levels correlated positively with age and negatively with BMI, body fat, LVMI, SVi and the E/E' index. Multivariate regression analysis confirmed that age and the $\mathrm{E} / \mathrm{E}$ ' index were independent predictors of the adiponectin level in the AS group. Thus, the diastolic dysfunction that is typical for AS influenced adiponectin concentration.

Stojanovic et al. [31], similar to the present findings, found that adiponectin levels correlated with age, $\mathrm{BMI}$ and the $\mathrm{E} / \mathrm{E}^{\prime}$ index in patients with metabolic syndrome and/or CAD. On the other hand, in patients with hypertrophic cardiomyopathy, plasma adiponectin levels were associated with an impaired LV systolic function but only slightly with $\mathrm{E} / \mathrm{E}$ ' index [33].

Positive correlations were found in leptin levels with BMI and body fat\%. Generally, leptin, which is a mediator of the long-term regulation of energy balance, suppresses food intake [34]. Subjects with high plasma leptin levels have a better prognosis, thus suggesting a protective role of leptin in overweight/mild obesity [35]. On the other hand, overweight and obesity are associated with hyperleptinemia secondary to an impaired sensitivity of leptin receptors [36]. Recently, Karmazyn et al. [37] concluded that leptin is a cardiac hypertrophic factor and hyperleptinemia is associated with cardiovascular risk, especially as it pertains to heart failure. This can be of importance in regards to AS-mediated hypertrophy and/or CAD. As presented above, the presented subjects with AS and CAD were characterized by increased serum leptin levels compared to AS patients without CAD. Further studies are needed to evaluate these interesting concepts.

Regarding adipokines levels, it should also be taken into account the specificity of the population herein - relatively older subjects with AS. Schautz et al. [38] concluded that age-related changes in leptin and adiponectin levels are opposed to each other and are partly independent of adiposity and body fat distribution.

\section{Limitations of the study}

A limitation of the current study could be the relatively small number of patients. It should be stressed, however, that the study was conducted in a prospective fashion, which undoubtedly represents its methodological strength. It is also agreed that the division of the AS cohort into the subgroups PLFLG AS and NFHG AS had limitations related to the number of subjects. However, a well-known PLFLG AS clinical characteristic suggested an abnormal adipokine profile compared to NFHG AS.

An echocardiographic evaluation, especially in older, obese patients, has limitations regarding the LVOT measurements, and finally the AS severity calculation. These problems were apparent, this is why all echocardiographic measurements were done very precisely by an experienced sonographer. Vascular response to sublingual nitroglycerin was not assessed because of the severity of AS. Moreover, adipokines levels were measured at one point only.

\section{Conclusions}

Severe degenerative AS with preserved EF is not associated with any change in the adipokine serum profile. Adipokines serum levels are modified by co-existing atherosclerosis but not the typical cardiovascular risk factors or the hemodynamic type of AS. The adiponectin serum level in patients with severe AS with preserved $\mathrm{EF}$ is related to age and LV diastolic dysfunction.

Funding: The grant for scientific research in the field of valvular heart disease was funded by the Medical University of Silesia, Katowice, Poland.

Conflict of interest: None declared 


\section{References}

1. Hotta K, Funahashi T, Arita Y, et al. Plasma concentrations of a novel, adipose-specific protein, adiponectin, in type 2 diabetic patients. Arterioscler Thromb Vasc Biol. 2000; 20(6): 1595-1599, indexed in Pubmed: 10845877.

2. Lam KSL, Xu A. Adiponectin: protection of the endothelium. Curr Diab Rep. 2005; 5(4): 254-259, indexed in Pubmed: 16033674.

3. Chen H, Montagnani M, Funahashi T, et al. Adiponectin stimulates production of nitric oxide in vascular endothelial cells. J Biol Chem. 2003; 278(45): 45021-45026, doi: 10.1074/jbc. M307878200, indexed in Pubmed: 12944390.

4. Wang M, Wang D, Zhang Y, et al. Adiponectin increases macrophages cholesterol efflux and suppresses foam cell formation in patients with type 2 diabetes mellitus. Atherosclerosis. 2013; 229(1): 62-70, doi: 10.1016/j.atherosclerosis.2013.01.017, indexed in Pubmed: 23466101.

5. Folco EJ, Rocha VZ, López-Ilasaca M, et al. Adiponectin inhibits pro-inflammatory signaling in human macrophages independent of interleukin-10. J Biol Chem. 2009; 284(38): 25569-25575, doi: 10.1074/jbc.M109.019786, indexed in Pubmed: 19617629.

6. Hotta K, Funahashi T, Bodkin NL, et al. Circulating concentrations of the adipocyte protein adiponectin are decreased in parallel with reduced insulin sensitivity during the progression to type 2 diabetes in rhesus monkeys. Diabetes. 2001; 50(5): 1126-1133, indexed in Pubmed: 11334417.

7. Peri-Okonny PA, Ayers C, Maalouf N, et al. Adiponectin protects against incident hypertension independent of body fat distribution: observations from the Dallas Heart Study. Diabetes Metab Res Rev. 2017; 33(2), doi: 10.1002/dmrr.2840, indexed in Pubmed: 27455039.

8. Pratesi A, Di Serio C, Orso F, et al. Prognostic value of adiponectin in coronary artery disease: Role of diabetes and left ventricular systolic dysfunction. Diabetes Res Clin Pract. 2016; 118: 58-66, doi: 10.1016/j.diabres.2016.04.003, indexed in Pubmed: 27344545.

9. Sharma S, Colangelo LA, Lloyd-Jones D, et al. Longitudinal associations between adiponectin and cardiac structure differ by hypertensive status: Coronary Artery Risk Development in Young Adults. Cardiovasc Endocrinol. 2016; 5(2): 57-63, doi: 10.1097/ XCE.0000000000000080, indexed in Pubmed: 27525195.

10. Paolisso G, Tagliamonte MR, Galderisi M, et al. Plasma leptin concentration, insulin sensitivity, and 24-hour ambulatory blood pressure and left ventricular geometry. Am J Hypertens. 2001; 14(2): 114-120, indexed in Pubmed: 11243301.

11. Puurunen VP, Lepojärvi ES, Pïra OP, et al. High plasma leptin levels are associated with impaired diastolic function in patients with coronary artery disease. Peptides. 2016; 84: 17-21, doi: 10.1016/j.peptides.2016.08.002, indexed in Pubmed: 27524739.

12. Schulze PC, Kratzsch J, Linke A, et al. Elevated serum levels of leptin and soluble leptin receptor in patients with advanced chronic heart failure. Eur J Heart Fail. 2003; 5(1): 33-40, indexed in Pubmed: 12559213.

13. Steppan CM, Bailey ST, Bhat S, et al. The hormone resistin links obesity to diabetes. Nature. 2001; 409(6818): 307-312, doi: 10.1038/35053000, indexed in Pubmed: 11201732.

14. Ohmori R, Momiyama Y, Kato R, et al. Associations between serum resistin levels and insulin resistance, inflammation, and coronary artery disease. J Am Coll Cardiol. 2005; 46(2): 379-380, doi: 10.1016/j.jacc.2005.04.022, indexed in Pubmed: 16022972.
15. Fukuhara A, Matsuda M, Nishizawa M, et al. Visfatin: a protein secreted by visceral fat that mimics the effects of insulin. Science. 2005; 307(5708): 426-430, doi: 10.1126/science.1097243, indexed in Pubmed: 15604363.

16. Lin YT, Jian DY, Kwok CF, et al. Visfatin promotes foam cell formation by dysregulating CD36, SRA, ABCA1, and ABCG1 expression in RA264.7 macrophages. Shock. 2016; 45(4): 460468, doi: 10.1097/SHK.0000000000000529, indexed in Pubmed: 26536203.

17. Xiao J, Xiao ZJ, Liu ZG, et al. Involvement of dimethylarginine dimethylaminohydrolase-2 in visfatin-enhanced angiogenic function of endothelial cells. Diabetes Metab Res Rev. 2009; 25(3): 242-249, doi: 10.1002/dmrr.939, indexed in Pubmed: 19229883.

18. Mazaherioun M, Hosseinzadeh-Attar MJ, Janani L, et al. Elevated serum visfatin levels in patients with acute myocardial infarction. Arch Iran Med. 2012; 15(11): 688-692, doi: 0121511/ AIM.008, indexed in Pubmed: 23102245.

19. Eleid MF, Sorajja P, Michelena HI, et al. Flow-gradient patterns in severe aortic stenosis with preserved ejection fraction: clinical characteristics and predictors of survival. Circulation. 2013; 128(16): 1781-1789, doi: 10.1161/CIRCULATIONAHA.113.003695, indexed in Pubmed: 24048203.

20. Hachicha Z, Dumesnil JG, Bogaty P, et al. Paradoxical low-flow, low-gradient severe aortic stenosis despite preserved ejection fraction is associated with higher afterload and reduced survival. Circulation. 2007; 115(22): 2856-2864, doi: 10.1161/CIRCULATIONAHA.106.668681, indexed in Pubmed: 17533183.

21. Baumgartner H, Hung J, Bermejo J, et al. Echocardiographic assessment of valve stenosis: EAE/ASE recommendations for clinical practice. Eur J Echocardiogr. 2009; 10(1): 1-25, doi: 10.1093/ ejechocard/jen303, indexed in Pubmed: 19065003.

22. Dieplinger B, Poelz W, Haltmayer M, et al. Hypoadiponectinemia is associated with symptomatic atherosclerotic peripheral arterial disease. Clin Chem Lab Med. 2006; 44(7): 830-833, doi: 10.1515/CCLM.2006.145, indexed in Pubmed: 16776628.

23. Matsuura F, Oku H, Koseki M, et al. Adiponectin accelerates reverse cholesterol transport by increasing high density lipoprotein assembly in the liver. Biochem Biophys Res Commun. 2007; 358(4): 1091-1095, doi: 10.1016/j.bbrc.2007.05.040, indexed in Pubmed: 17521614.

24. Ouchi N, Kihara S, Arita Y, et al. Novel modulator for endothelial adhesion molecules: adipocyte-derived plasma protein adiponectin. Circulation. 1999; 100(25): 2473-2476, indexed in Pubmed: 10604883.

25. Otsuka F, Sugiyama S, Kojima S, et al. Plasma adiponectin levels are associated with coronary lesion complexity in men with coronary artery disease. J Am Coll Cardiol. 2006; 48(6): 1155-1162, doi: 10.1016/j.jacc.2006.05.054, indexed in Pubmed: 16978998.

26. Kawano J, Arora R. The role of adiponectin in obesity, diabetes, and cardiovascular disease. J Cardiometab Syndr. 2009; 4(1): 44-49, doi: 10.1111/j.1559-4572.2008.00030.x, indexed in Pubmed: 19245516.

27. Gucuk Ipek E, Guray U, Guray Y, et al. Relationship between serum adiponectin levels and calcific aortic valve disease. Kardiol Pol. 2013; 71(3): 241-246, doi: 10.5603/KP.2013.0035, indexed in Pubmed: 23575778.

28. Kolasa-Trela R, Miszalski-Jamka T, Grudzień G, et al. Adiponectin, leptin, and resistin in patients with aortic stenosis without concomitant atherosclerotic vascular disease. Pol Arch Med Wewn. 2011; 121(10): 352-359, indexed in Pubmed: 21952524.

29. Mohty D, Pibarot P, Després JP, et al. Age-related differences in the pathogenesis of calcific aortic stenosis: the potential role 
Cardiology Journal 2019, Vol. 26, No. 5

of resistin. Int J Cardiol. 2010; 142(2): 126-132, doi: 10.1016/j. ijcard.2008.12.068, indexed in Pubmed: 19162347.

30. Mohty D, Pibarot P, Côté N, et al. Hypoadiponectinemia is associated with valvular inflammation and faster disease progression in patients with aortic stenosis. Cardiology. 2011; 118(2): 140-146, doi: 10.1159/000327588, indexed in Pubmed: 21597293.

31. Stojanović S, Ilić MD, Ilić S, et al. The significance of adiponectin as a biomarker in metabolic syndrome and/or coronary artery disease. Vojnosanit Pregl. 2015; 72(9): 779-784, indexed in Pubmed: 26554109.

32. Chiara TDi, Argano C, Scaglione A, et al. Circulating adiponectin: a cardiometabolic marker associated with global cardiovascular risk. Acta Cardiol. 2015; 70(1): 33-40, doi: 10.2143/ AC.70.1.3064591, indexed in Pubmed: 26137801.

33. Kitaoka H, Kubo T, Okawa M, et al. Plasma adiponectin levels and left ventricular remodeling in hypertrophic cardiomyopathy. Int Heart J. 2010; 51(1): 51-55, indexed in Pubmed: 20145352.
34. Klok MD, Jakobsdottir S, Drent ML. The role of leptin and ghrelin in the regulation of food intake and body weight in humans: a review. Obes Rev. 2007; 8(1): 21-34, doi: 10.1111/j.1467789X.2006.00270.x, indexed in Pubmed: 17212793.

35. Simiti LA, Todor I, Stoia MA, et al. Better prognosis in overweight/obese coronary heart disease patients with high plasma levels of leptin. Clujul Med. 2016; 89(1): 65-71, doi: 10.15386/ cjmed-524, indexed in Pubmed: 27004027.

36. Kahn B, Flier J. Obesity and insulin resistance. J Clin Invest. 2000; 106(4): 473-481, doi: 10.1172/jci10842.

37. Karmazyn M, Gan XT, Rajapurohitam V. The potential contribution of circulating and locally produced leptin to cardiac hypertrophy and failure. Can J Physiol Pharmacol. 2013; 91(11): 883-888, doi: 10.1139/cjpp-2013-0057, indexed in Pubmed: 24117255.

38. Schautz B, Later W, Heller M, et al. Impact of age on leptin and adiponectin independent of adiposity. Br J Nutr. 2012; 108(2): 363-370 doi: 10.1017/S0007114511005605, indexed in Pubmed: 22370102. 